\title{
A Adoção e o Princípio do Prioritário Interesse da Criança
}

\author{
The Adoption and the Best Interest of Child Principle
}

\author{
Luciano Matheus Rahal \\ LFG/Anhanguera, Pós-Graduação Lato Sensu em Direito de Família e Sucessões da Rede de Ensino. PR, Brasil. \\ E-mail: rahalluciano@hotmail.com
}

\begin{abstract}
Resumo
O presente trabalho, à luz da Constituição Federal, Lei no 8.069/90 (ECA) e Lei no 13.257/2016 (primeira infância), além de produções doutrinárias e pesquisas realizadas em nível nacional, pretende uma releitura da regra da prevalência da família natural, com o resgaste da relevância do princípio do prioritário interesse da criança. Por meio de método dedutivo se demonstra que o fracasso na inserção de crianças, ainda na primeira infância, em famílias substitutas, na forma de adoção, possui impactos irreversíveis sobre estas pessoas em formação, realidade esta que pode ser alterada caso haja uma mudança de paradigma por parte da rede de proteção, focando as intervenções sempre no prioritário interesse da criança, seja no contexto da família natural ou não.
\end{abstract}

Palavras-chave: Adoção. Prioritário Interesse da Criança. Primeira Infância.

\begin{abstract}
The present work, in the light of the Federal Constitution, Federal Law no. 8.069 / 90 (ECA) and law n.13.257 / 2016 (early childhood), in addition to doctrinal productions and surveys conducted at the national level, intends to re-read the prevalence rule of the natural family, with the regain of relevance of the priority interest of child principle. Through a deductive method, it will be demonstrated that the failure to insert children, in early childhood, into substitute families in the form of adoption, has irreversible impacts on these people in formation, a reality that can be changed in case there is a paradigm shift by part of the safety net, focusing on interventions always on the best interest of the child, whether in the context of the natural family or not.
\end{abstract}

Keywords: Adoption. Best Interest of the Child. Early Childhood.

\section{Introdução}

Muitas crianças no Brasil em condições de serem encaminhadas para adoção, por se tratar de hipótese clara de destituição do poder familiar (negligência, maus tratos, abandono etc.), acabam não tendo este destino apesar do elevado número de pretendentes habilitados no Cadastro Nacional de Adoção.

Nesse sentido, o presente trabalho científico pretende demonstrar que a insistência exagerada na preservação do vínculo com os genitores (família nuclear) e a preferência cultural conferida à família extensa, apesar da pouca ou nenhuma vinculação afetiva com o infante, vem limitando as possibilidades de inserção destes incapazes em famílias substitutas na modalidade de adoção ainda na primeira infância, violando o princípio do prioritário interesse da criança.

Dessa forma, a excessiva insistência em preservar os vínculos familiares com os genitores, ou a manutenção da criança sob a guarda da família estendida, notadamente avós, tios, primos e outros, nas hipóteses em que seria evidente a necessidade de destituição de poder familiar, vem dificultando a adoção de crianças em baixa idade, aumentando o número de "órfãos" nas instituições de acolhimento, que acabam por atingir a maioridade sem a indispensável inclusão familiar.

O presente estudo pretende instigar uma reflexão visando mudança de paradigma por parte do sistema de Justiça (Juiz, Ministério Público, Defensoria Pública e Conselho Tutelar), com enfoque no prioritário interesse da criança, e na célere e efetiva intervenção no sentido de definir a aptidão ou não dos genitores biológicos em continuar exercendo o poder familiar, de modo a permitir que mais crianças tenham a oportunidade de serem criadas em um ambiente que permita seu desenvolvimento físico, mental, moral, espiritual e social, em condições de liberdade e de dignidade.

Pretende-se ressaltar a urgente necessidade de mudança de paradigma aos operadores do direito no sentido de ponderar as deficiências e vulnerabilidades da família natural à luz do prioritário interesse da criança, preferencialmente, até seis anos de idade (primeira infância).

Em outras palavras, as vulnerabilidades do contexto da família natural, como: drogadição, miséria extrema e crônica e baixíssima instrução que podem resultar em maus tratos, negligência e abusos, entre outros casos insuperáveis ou de difícil ou improvável superação, não podem obstaculizar o acesso da criança à família substituta. 


\section{Desenvolvimento}

\subsection{Metodologia}

O presente estudo, portanto, à luz da atualizada legislação, produções doutrinárias e pesquisas, utilizando método dedutivo, teve por objeto a releitura deste importante princípio (prioritário interesse da criança), visando adequá-lo aos demais valores e princípios balizadores presentes na Constituição Federal, Lei no 8.069/90 (ECA) e Lei no 13.257/2016 (marco legal da primeira infância).

\subsection{O panorama atual da adoção no Brasil}

Conforme reiteradamente vem revelando as mais diversas pesquisas em nível nacional ao longo dos anos, o Brasil padece de uma contradição que não vem conseguindo superar: há muitas crianças e adolescentes em condições de serem adotados e um número ainda maior de pretendentes à adoção, aptos a exercerem o poder familiar, porém os índices de adoções regulares (excluídas as chamadas adoções "à brasileira") são baixíssimos.

A primeira grande pesquisa realizada, em nível nacional, após a implantação do Cadastro Nacional de Adoção (CNA), que padronizou o cadastro tanto de pretendentes quanto de crianças/adolescentes aptas à adoção, concluiu:

De acordo com os dados do Cadastro Nacional de Crianças Acolhidas (CNCA) relativos ao mês de junho de 2012, existiam 40.340 crianças e adolescentes acolhidos em instituições de acolhimento ou estabelecimentos sustentados por organizações não governamentais (ONGs), comunidades e instituições religiosas em todo o território nacional. Parte dessas crianças e adolescentes compõem as 5.281 crianças e adolescentes aptas à adoção registradas no Cadastro Nacional de Adoção (CNA). Quando esse universo é comparado ao total de pretendentes à adoção, devidamente cadastrados no CNA (28.151 pessoas), verifica-se a proporção aproximada de cinco pretendentes para cada criança cadastrada no CNA. Observa-se que existe um contingente significativamente maior de pessoas interessadas em adotar em relação a crianças e adolescentes aptos à adoção (CNJ, 2013).

Estes dados revelam que há grande número de pretendentes à adoção (28.151 pessoas) e elevado número de crianças/adolescentes em situação de extrema vulnerabilidade (40.340 crianças), muitas das quais poderiam ser inseridas em família substituta na forma de adoção em número muito superior às formalmente cadastradas (5.281 crianças), caso houvesse mudança de paradigma, como se passa a discorrer mais adiante.

Esta aparente contradição (muitos pretendentes, muitas crianças, mas poucas adoções), possui uma série de motivos de ordem jurídica, cultural, econômica, regional, porém se destaca, com absoluta segurança, como a razão primeira desta incongruência, o perfil específico das crianças pretendidas pelos cadastrados, os quais, via de regra, desejam crianças de até cinco anos de idade $(92,7 \%)$, ao passo que inversamente proporcional a este perfil o cadastro nacional revela que apenas $8,8 \%$ das crianças possuem esta característica.
Dessa forma, segundo os dados extraídos de referida pesquisa, 92,7\% das pessoas cadastradas pretendem um universo de $8,8 \%$ das crianças, equação esta que, por consequência, leva a um frustrante e inaceitável resultado final: elevado número de órfãos nas entidades de acolhimento por todo o Brasil.

Estes indicadores, portanto, sugerem que a idade da criança e do adolescente é um entrave significativo para a adoção, circunstância que está diretamente relacionada à atuação tardia da rede de proteção à infância (conselho tutelar, secretaria de saúde, CREAS, CRAS, Ministério Público, Judiciário etc.) ou a uma atuação excessivamente leniente desta rede com a família natural, em prejuízo ao prioritário interesse da criança.

Outra significativa fonte de pesquisa, neste sentido, é produto de um cuidadoso trabalho da Associação Brasileira de Jurimetria - ABJ, denominado: Tempo dos Processos Relacionados à Adoção no Brasil: Uma análise sobre os impactos da atuação do Poder Judiciário, o qual, inclusive, apresentou sugestões para incrementar o número de adoções e agilizar sua tramitação:

- Agilizar a guarda da criança e cumprir prazos;

- Evoluir o diálogo entre juízes, setor técnico e promotoria;

- Aprimorar os cursos com adotantes;

- Criação de uma vara especializada somente em adoção e destituição;

- Reduzir a insistência em manter as famílias biológicas, permitindo assim a destituição para que se possa fazer a adoção ( ABJ, 2104).

Nesse contexto, quanto menor a idade em que a criança é inserida no CNA (que dependerá, muitas vezes, da maior ou menor insistência em mantê-la na família biológica), maiores suas chances em ser adotada e, por conseguinte, de sofrer uma intervenção positiva em sua formação por meio de uma família que assegure um "ambiente que garanta seu desenvolvimento integral” (BRASIL, 1990).

\subsection{O impacto da família na Primeira Infância}

É inegável a importância da denominada "Primeira Infância" na formação biológica, ética, cultural, motora, afetiva e psicológica da criança, tanto que a Lei Federal $n^{\circ}$ 13.257/2016 (Marco Legal da Primeira Infância), em seu artigo $1^{\circ}$, reconheceu a necessidade de "atenção à especificidade e à relevância dos primeiros anos de vida no desenvolvimento infantil e no desenvolvimento do ser humano" (BRASIL, 2016), definindo-a, para os efeitos da lei, como o período que abrange os primeiros seis anos completos ou 72 meses de vida da criança.

Ao longo da história, a família vem sendo o principal fator de influência na formação da criança, constatação esta que levou sabiamente o constituinte de 1988 a reconhecer a necessidade de lhe conferir especial proteção e reconhecê-la como base da sociedade, criando dispositivo legal específico 
para tanto (BRASIL, 1988).

E não é sem motivos, estudiosos das mais diversas áreas do conhecimento vem cada vez mais evidenciando, empiricamente, a relevância da família na formação da criança, pessoa ainda em formação.

Nesse sentido, o professor Lidz (1983, p.68) pontuou:

A família exerce a mais precoce e a mais persistente influência que atinge o bebê ainda não formado e a criança pequena, para quem o modo de vida dos pais e da família são o modo de vida, o único que a criança conhece. Todas as experiências subsequentes são percebidas, compreendidas e respondidas emocionalmente de acordo com os fundamentos estabelecidos na família. O modo de vida da família e os padrões da criança de a ele reagir tornam-se integralmente incorporados nesta última que podem ser considerados determinantes de sua formação constitucional.

Referida influência fundante na vida da criança, entretanto, pode ser um instrumento preciosíssimo para a formação de um cidadão com valores como a igualdade e a justiça, visando construção de uma sociedade fraterna, pluralista e sem preconceitos, fundada na harmonia social, como prevê o preâmbulo de Carta Constitucional (BRAIL, 1988), ou exatamente o contrário.

Aliás, o mesmo saudoso professor continua, em sua obra, discorrendo sobre a relevância dos pais neste contexto:

O desamparo e a dependência prolongados das crianças exigem que elas sejam criadas por seus pais ou substitutos, para os quais o bem-estar da criança seja tão importante, se não mais importante, que o seu próprio [...].

[...] pais instáveis e grosseiramente incompatíveis muitas vezes são influências perturbadoras através de todos os anos de desenvolvimento da criança; e tais influências pervasivas são muitas vezes mais significantes em estabelecer traços ou distúrbios da personalidade nas crianças do que as dificuldades durante uma fase específica de desenvolvimento (LIDZ, 1983, p.74).

Em outras palavras, nada mais prejudicial para o desenvolvimento de uma criança (e, por consequência, de uma nação) do que pais abusadores, negligentes, cruéis, exploradores, omissos e violentos, continuarem a exercer a guarda de seus filhos, muitas vezes, sob o olhar leniente/ tolerante da rede de proteção, em um país no qual este comportamento deveria ser duramente punido e combatido, conforme previsto em lei (BRASIL, 1990).

E mais grave: nada mais prejudicial do que ceifar as crianças criadas nestas condições de terem a oportunidade de serem inseridas em uma família substituta na qual estas circunstâncias não estejam presentes.

\subsection{A indispensável mudança de paradigma: prioridade absoluta da criança}

O art. 227 da Constituição Federal (BRASIL, 1988) deixa claro o compromisso do Brasil com a Doutrina da Proteção Integral, assegurando à criança a condição de sujeito de direitos fundamentais. Inverte-se, desde então, o foco da prioridade. No sistema jurídico anterior, privilegiava-se o interesse do adulto (doutrina da situação irregular). Com a
Nova Carta, o interesse prioritário passa a ser o da criança, em que a criança não é mais mero objeto de direito, mas sim sujeito de direitos constitucionalmente reconhecidos.

O marco emblemático desta mudança de paradigma foi, sem dúvida alguma, a adoção do princípio do prioritário interesse da criança pelo ordenamento jurídico brasileiro, decorrente de normativa introduzida pela Convenção Internacional sobre os Direitos da Criança, aprovada pela Assembleia Geral das Nações Unidas, de 20 de novembro de 1989.

O sistema jurídico brasileiro cristalizou aludida garantia por meio do artigo $4^{\circ}$ da Lei Federal $n^{\circ} 8.069 / 90$ - Estatuto da Criança e do Adolescente:

Art. $4^{\text {o }}$ É dever da família, da comunidade, da sociedade em geral e do poder público assegurar, com absoluta prioridade, a efetivação dos direitos referentes à vida, à saúde, à alimentação, à educação, ao esporte, ao lazer, à profissionalização, à cultura, à dignidade, ao respeito, à liberdade e à convivência familiar e comunitária (BRASIL, 1990).

Entretanto, quando se trata de assegurar estes mesmos direitos, no âmbito da família natural, vem-se relativizando este princípio basilar por meio de uma interpretação equivocada dos artigos 19, 25, 39 da Lei no 8.069/90 (BRASIL, 1990), conferindo uma relevância quase que "sagrada" à família natural e extensa, como se os laços sanguíneos prevalecessem sobre os demais, mesmo quando inexistente ou quase nula a vinculação afetiva dos pais ou demais familiares extensos com a criança, ou ainda quando constatada a crônica violação dos direitos elementares por parte destes familiares biológicos.

A este respeito, a crítica da doutrina especializada não vem sendo diferente, a exemplo da renomada professora Maria Berenice Dias, vice-presidente nacional do IBDFAM:

Também é necessário retirar do Poder Judiciário - que não tem estrutura para tal - o encargo de caçar parentes na tentativa de entregar-lhes crianças que não tem para com eles vínculo de afinidade e afetividade. Além disso, a entrega à família extensa merece o devido acompanhamento, pois $80 \%$ das devoluções é feita pelos parentes que estavam com a guarda (DIAS, 2017).

Trata-se da triste constatação por parte de uma experiente especialista da área de direito de família acerca da equivocada abordagem que permeia a atuação de grande parte dos integrantes da rede de proteção, com gravíssimas e irreversíveis consequências às crianças envolvidas.

O primeiro grande equívoco consiste na insistência desarrazoada na permanência da criança junto à família natural, mesmo quando flagrante a incapacidade crônica dos genitores de exercerem de forma minimamente satisfatória o poder familiar.

Tem-se interpretado o referido artigo 19 do ECA de forma absoluta e desconectada de todo sistema de garantias, como se o fato da criança ter sido composta pelo material genético de um determinado homem e mulher tornasse este liame digno de uma tutela especial, mesmo em detrimento do superior 
interesse da criança que, neste caso, voltaria ao "status" de mero objeto de direito, regredindo sua tutela para a sistemática da odiosa doutrina da situação de risco, anteriormente à Lei ${ }^{\circ}$ 8.069/90 (BRASIL, 1990).

O segundo grande equívoco que esta compreensão distorcida do texto legal acarreta é a manutenção destes infantes em situação de risco sob os cuidados precários de uma família estendida sem vinculação afetiva e/ou condições mínimas de cuidado, interpretando-se que o referido artigo $39, \S 1^{\circ}$, somente autorizaria a adoção nas hipóteses em que "esgotados os recursos de manutenção da criança ou adolescente na família natural ou extensa".

Ocorre que este entendimento acaba por ignorar exatamente a norma conceitual do artigo 25, parágrafo único, da Lei $n^{\circ} 8.069 / 90$, a qual define como família extensa: "aquela que se estende para além da unidade pais e filhos ou da unidade do casal, formada por parentes próximos com os quais a criança ou adolescente convive e mantém vínculos de afinidade e afetividade" (BRASIL, 1990).

$\mathrm{O}$ dispositivo em referência, portanto, exige que estes parentes sejam próximos da criança, convivam com esta, e mantenham vínculos de afinidade e afetividade com ela.

$\mathrm{O}$ que se tem visto, entretanto, na prática, é a retirada da criança da mãe e/ou pai por alguma situação de grave risco pela rede de proteção e entrega a qualquer familiar que aceite permanecer com o infante, não importando o grau de parentesco, nem a prévia convivência e, principalmente, os eventuais laços de afetividade.

Nesse sentido, tolhe-se a criança injustificadamente do direito de ser criada em uma família (natural ou substituta) que assegure um ambiente que garanta seu desenvolvimento integral (BRASIL, 1990).

Tanto que por ocasião das audiências de instrução no curso das ações para destituição do poder familiar, na tentativa de impedir o sucesso destas demandas e a "retirada da criança da família", estes avôs, tios, primos, e irmãos (familiares extensos), mesmo sabidamente incapazes de oferecerem a esta criança condições para um desenvolvimento sadio, justificam a oposição ao pleito declarando simplesmente que não desejam que a criança deixe a família, como se o sangue do incapaz tivesse dotado de um componente transcendente que impedisse sua inserção em outro núcleo familiar.

$\mathrm{Na}$ verdade, trata-se do inato sentimento humano de perda da "posse", a mãe, o pai, os avós, os primos não aceitam reconhecer seus fracassos e incapacidades em oferecer aquilo que "suas" crianças têm garantido pela Constituição, e enxergam no julgamento destas ações de destituição do poder familiar um atestado judicial desta incapacidade.

Infelizmente, não se vislumbra o mesmo empenho dos mesmos familiares quando se trata de crianças em idade mais avançada (pré-adolescentes) ou adolescentes, exatamente a parcela de pessoas com menor probabilidade de adoção, fatalmente destinadas a atingirem a maioridade nas instituições de acolhimento ou constituindo precocemente uniões estáveis, como único meio de superar esta indesejável condição.

A mesma pesquisa já citada do CNJ (Conselho Nacional de Justiça) constatou que a partir dos 10 anos, as crianças/ adolescentes constituem 74,0\% dos cadastrados aptos à adoção, ao passo que apenas $1,2 \%$ dos pretendentes à adoção têm interesse em menores nesta faixa etária (CNJ, 2013).

Simplesmente, a conta não fecha e exige, no mínimo, uma sincera reflexão dos familiares e demais atores envolvidos, visando garantir a estas pessoas em desenvolvimento que seus direitos lhes sejam efetivamente assegurados, o mais precocemente possível.

\subsubsection{Consumo abusivo de drogas pelos pais como fator de risco aos filhos}

Neste contexto de fragilidade familiar, um elemento que vem assumindo um protagonismo negativo cada vez maior, impactando gravemente as crianças e os adolescentes, tem sido o consumo abusivo de substâncias entorpecentes por parte dos genitores.

Pais dependentes químicos vêm aniquilando toda uma geração de crianças e adolescentes, violando, das mais variadas formas (negligência, maus tratos, abandono, contato precoce com drogas etc.), os direitos mínimos destas pessoas em formação.

O saldo é trágico e demonstrado reiteradamente ao longo dos anos pelas mais diversas áreas do conhecimento. Neste sentido, recente artigo de pesquisadores da UFPR constatou:

[...] estudo mostra que famílias com abuso de substâncias pelos pais possuem maiores taxas de doenças mentais, desemprego, violência doméstica, delinquência, e de maior dependência dos serviços sociais, fato que tem gerado angústia, traumas e prejuízos para o desenvolvimento das crianças. [...] uso de drogas por seus pais pode trazer comprometimento funcional para esta criança, sendo os déficits em seu desenvolvimento atribuídos aos maus tratos dos cuidadores usuários de drogas. Há evidências que filhos de pais dependentes químicos tendem a entrar em orfanatos em idades mais tenras e são mais propensos a permanecer em um orfanato mais do que crianças maltratadas de famílias não afetadas pelo uso de drogas (SILVA; MAFTUM; MAZZA, 2014).

O consumo abusivo de drogas de fato é um dilema de saúde pública, possui raízes culturais e socioeconômicas de natureza extremamente complexas, e se mostrou imune às políticas repressivas das últimas décadas.

Entretanto, mesmo ciente deste peculiar contexto, no que se refere aos genitores de crianças em situação de risco decorrente do consumo abusivo de substâncias entorpecentes (lícitas ou não), estes fizeram uma escolha pessoal e toda escolha implica consequências, de modo que não se pode tolerar que a penalização por esta opção equivocada destes adultos autônomos recaia sobre o elo mais frágil desta cadeia: a criança (prioridade absoluta).

É dizer que se adultos optaram por se tornarem usuários e, posteriormente, dependentes do uso de entorpecentes, não se pode privar, por outro lado, a criança do direito 
constitucionalmente assegurado de crescer em um lar a salvo de toda forma de negligência, de discriminação, de exploração, de violência, de crueldade e de opressão (BRASIL, 1988).

É bem verdade que, de outra parte, não se pode prescindir do olhar social diferenciado para as famílias em situação de extrema vulnerabilidade, sem o qual se corre o risco de impor um padrão cultural, moral e socioeconômico alheios, desprezando as mazelas, as virtudes e peculiaridades de cada família e comunidade na qual se encontra inserida.

Tanto que o próprio Estatuto da Criança e do Adolescente, sensível a estas vicissitudes, trouxe uma regulamentação própria para a criança e adolescente indígena ou proveniente de comunidade remanescente de quilombo, além de dispositivos visando preservação da autonomia, dos valores, ideias e crenças, dos espaços e objetos pessoais (BRASIL, 1990) das crianças e adolescentes, elementos estes representativos de seu contexto.

Porém, o que se advoga por meio do presente trabalho é que uma interpretação enviesada por uma ideologia de "vitimização social" distorcida, sob o cômodo e genérico argumento da "falha da atuação da rede de proteção", tem levado ao enfraquecimento do princípio da responsabilidade parental (BRASIL, 1990) (autonomia da vontade), sob a justificativa de que estes genitores seriam um mero produto do meio em que foram constituídos e da falta de políticas públicas efetivas visando a superação da situação de risco crônica.

É dizer, sob a justificativa de evitar uma condenável política higienista, que se vem de outro extremo "punindose" as crianças mantendo-as em famílias funcionalmente desajustadas (e.g. profundamente envolvida com a dependência química crônica dos pais) e indiferentes às tentativas de resgate por parte da rede de proteção, sob o argumento da "preservação dos vínculos familiares naturais" que, neste caso, vem tomando equivocadamente contornos de princípio absoluto e superior aos demais, o que, obviamente, nunca foi a intenção do legislador.

Cada mês de inércia ou leniência do poder público, da família e da sociedade em agir perante uma situação de extrema vulnerabilidade pode implicar na inviabilidade de inserção de uma criança, preferencialmente ainda na primeira infância, em uma família saudável que tenha condições e interesse em construir laços genuínos de afeto, fundamentais, como visto, para o desenvolvimento de qualquer ser humano.

\section{Conclusão}

Como visto, demonstrou-se que os princípios da proteção integral e do prioritário interesse da criança devem ser os principais balizadores no enfrentamento das questões envolvendo crianças e adolescentes em situação de risco e na eventual inserção destes menores em famílias substitutas na modalidade de adoção.

Destaca-se a urgente necessidade de que todos os integrantes da rede de proteção à infância, independentemente da função exercida, quais sejam, juízes, promotores, defensores públicos, advogados, conselheiros tutelares, enfermeiros, assistentes sociais, psicólogos, pais, familiares extensos, entre outros, façam uma releitura de suas intervenções a partir do ponto de vista da extrema fragilidade de uma criança violada em seus direitos em seu próprio núcleo familiar (e não do ponto de vista de seus pais biológicos).

Viu-se que o baixíssimo índice de adoções no Brasil se deve, entre outros fatores, principalmente, à avançada idade dos menores aptos juridicamente a serem adotados (adoção tardia) que, por sua vez, decorre, também, da exagerada leniência da rede de proteção para com a família natural e extensa no aguardo de uma eventual e incerta superação da situação de risco.

Como visto, o custo desta demora/inércia é intoleravelmente alto para as crianças, para o país.

Diante do exposto, os trabalhos realizados demonstraram que a intervenção dos atores de proteção deve ser a mais precoce possível, preferencialmente, ainda durante a primeira infância, assegurando todo o apoio para que a família natural tenha condições de oferecer um ambiente saudável para a prole, em um primeiro momento.

Porém, superada esta etapa, em se constatando a persistência da situação de risco, apesar das intervenções, é direito da criança violada o cumprimento do mandamento constitucional previsto no artigo 227 da Carta Magna, colocando-a a salvo de toda forma de negligência, de discriminação, de exploração, de violência, de crueldade e de opressão, mesmo que no âmbito de uma família substituta, na excepcional modalidade de adoção.

Não se trata de amoldar uma criança para tolerar a convivência em uma família disfuncional, abusadora de seus direitos, mas garantir à criança um direito universalmente assegurado: um nível de vida adequado ao seu desenvolvimento físico, mental, espiritual, moral e social.

\section{Referências}

ABJ - Associação Brasileira de Jurimetria. Tempo dos processos relacionados à adoção no Brasil: uma análise sobre os impactos da atuação do Poder Judiciário. 2014. Disponível em: $<\mathrm{http}: /$ www.cnj.jus.br/files/conteudo/destaques/arquivo/2015/06/3858b 9371bdbffd88b31e429ed8f4773.pdf.> Acesso em: 17 out. 2018.

BRASIL. Constituição (1988). Constituição da República Federativa do Brasil.

BRASIL. Estatuto da Criança e do Adolescente (1990). Lei ${ }^{\circ}$ 8.069, de 13 de julho de 1990.

BRASIL. Estatuto da Primeira Infância (2016). Lei no ${ }^{\circ} 13.257$, de 08 de março de 2016.

CNJ. Encontros e desencontros da adoção no Brasil: uma análise do Cadastro Nacional de Adoção do Conselho Nacional de Justiça, presidente Ministro Joaquim Barbosa. 2013. Disponível em: $\quad<$ http://www.cnj.jus.br/images/pesquisas-judiciarias/ Publicacoes/pesq_adocao_brasil.pdf.> Acesso em 17 out. 2018.

CONVENÇÃO INTERNACIONAL SOBRE OS DIREITOS DA CRIANÇA, aprovada pela Assembleia Geral das Nações 
RAHAL, L.M.

Unidas em 20 de novembro de 1989, promulgada pelo Decreto Presidencial no 99.710 de 1990.

DIAS, M.B. Manual de direito das famílias. São Paulo: Revista dos Tribunais, 2017.

DIAS, M.B. Adoção: um direito que não existe. Rev. Digital IBDFAM. 2018. Disponível em <http://www.ibdfam.org.br/ noticias $/ 6535 / \mathrm{Ado} \% \mathrm{C} 3 \% \mathrm{~A} 7 \% \mathrm{C} 3 \% \mathrm{~A} 30 \% 3 \mathrm{~A}+\mathrm{um}+$ direito + que + n\%C3\%A3o+existe.> Acesso em: jan. 2019.
LIDZ, T. A pessoa: seu desenvolvimento durante o ciclo vital. Porto Alegre: Artes Médicas, 1983.

SILVA, D.I.; MAFTUM, M.A.; MAZZA, V.A. Vulnerabilidade no Desenvolvimento da criança: influência dos elos familiares fracos, dependência química e violência doméstica. Texto Contexto Enferm., v.23, n.4, p.1087-1094. 2013. doi: http:// dx.doi.org/10.1590/0104-07072014001700013.. 